University of Nebraska - Lincoln

DigitalCommons@University of Nebraska - Lincoln

Faculty Publications from the Harold W. Manter Laboratory of Parasitology

2-1997

\title{
Cucullanus palmeri n. sp. (Nematoda: Cucullanidae) from the Batfish Ogcocephalus nasutus in the Gulf of Mexico
}

John L. Crites

Ohio State University

Robin M. Overstreet

Gulf Coast Research Laboratory, robin.overstreet@usm.edu

Follow this and additional works at: https://digitalcommons.unl.edu/parasitologyfacpubs

Part of the Parasitology Commons

Crites, John L. and Overstreet, Robin M., "Cucullanus palmeri n. sp. (Nematoda: Cucullanidae) from the Batfish Ogcocephalus nasutus in the Gulf of Mexico" (1997). Faculty Publications from the Harold W. Manter Laboratory of Parasitology. 447.

https://digitalcommons.unl.edu/parasitologyfacpubs/447

This Article is brought to you for free and open access by the Parasitology, Harold W. Manter Laboratory of at DigitalCommons@University of Nebraska - Lincoln. It has been accepted for inclusion in Faculty Publications from the Harold W. Manter Laboratory of Parasitology by an authorized administrator of DigitalCommons@University of Nebraska - Lincoln. 


\title{
CUCULLANUS PALMERI N. SP. (NEMATODA: CUCULLANIDAE) FROM THE BATFISH OGCOCEPHALUS NASUTUS IN THE GULF OF MEXICO
}

\author{
John L. Crites ${ }^{\star}$ and Robin M. Overstreet $†$ \\ Gulf Coast Research Laboratory, Institute of Marine Sciences, University of Southern Mississippi, Ocean Springs, Mississippi 39566
}

\begin{abstract}
Cucullanus palmeri n. sp. is described from the shortnose batfish, Ogcocephalus nasutus, in the Gulf of Mexico. This species is anatomically most similar to Cucullanus gendrei but differs from it in having a shorter esophagus and longer tail. Males differ in having a smaller gubernaculum and a different arrangement of a lateral caudal papilla. Cucullanus palmeri is readily distinguished from Cucullanus lophii, also from a lophiform fish host, in that the deirids and excretory pore are not posterior to the posterior end of the esophagus like in C. lophii.
\end{abstract}

Specimens of the shortnose batfish, Ogcocephalus nasutus (Valenciennes), collected from the Gulf of Mexico for display and drug studies (Schleser and Alvarado, 1992) at the Dallas Aquarium contained nematodes in their intestine. These nematodes, collected by David M. Schleser and Tom Alvarado at the Aquarium, were sent initially to Dr. John Greve of Iowa State University, who determined them to be Cucullanus sp. (see Chabaud, 1978) and then sent them to the Gulf Coast Research Laboratory for species identification. Following that, David Schleser sent us fixed batfishes for both identification and examination for additional nematodes. No cucullanid nematodes are known from batfishes, and this report describes the new species from a batfish in the Gulf of Mexico.

\section{MATERIALS AND METHODS}

Specimens were fixed in $10 \%$ formalin and preserved in $70 \%$ ethyl alcohol. Some were subsequently cleared by evaporating the alcohol from a 5-part glycerine : 95-part alcohol solution. Specimens for study using scanning electron microscopy (SEM) were sonicated, hydrated, buffered in $0.1 \mathrm{M}$ sodium cacodylate $(\mathrm{NaCaC})$, postfixed in $\mathrm{OsO}_{4}$, rinsed in $0.1 \mathrm{M} \mathrm{NaCaC}$, dehydrated, critical point dried, and sputter-coated with gold. These worms were examined in a JEOL JSM-T330 scanning electron microscope. Because of the poor quality of photographs of some dirty, prefixed material, some were retouched to hide debris and charging. One specimen was sectioned in paraffin and stained with hematoxylin and eosin. Line drawings were prepared with the aid of a drawing tube. All nematodes used for measurements were mature males with spermatozoa or females with eggs. All measurements are given in micrometers unless otherwise indicated. Mean measurements are enclosed in parentheses and follow the ranges of all specimens.

\section{DESCRIPTION}

Cucullanus palmeri $\mathrm{n}$. sp.

$$
\text { (Figs. 1-23) }
$$

General: Body short, slender for cucullanid nematodes, widest near base of esophagus, decreasing slightly in width at anal region and then narrowing to tip of pointed tail. Cuticle 7-10 thick near midbody, with fine closely spaced transverse striations. Anterior region straight, with cephalic end rounded. Oral opening shaped as dorsoventrally elongate spindle, wider in mid-dorsal region, surrounded by collarette with 60 80 raised denticular thickenings. Cephalic end with circumoral group of 4 small inner papillae, with 4 large outer papillae, with 2 lateral amphids; all such structures external to collarette. Esophagus almost entirely muscular (with exception of imbedded esophageal glands), ex-

Received 20 May 1996; revised 19 August 1996; accepted 19 August 1996.

* Permanent address: Museum of Biodiversity, Ohio State University, Columbus, Ohio 43210

$\dagger$ To whom reprint requests should be sent. panded in width at both ends. Esophastome (pseudobuccal capsule) well developed; buccal frame with reniform structures and transverse plate present; sclerotized esophageal lining surrounding oblong dorsoventral funnel-shaped lumen for anterior two-fifths of esophageal length, becoming more triangular near posterior hiatus, consisting of 3 portions each supported by 6 longitudinal rodlike thickenings, 2 each; points where 3 portions join forming sharp processes extending into esophageal tissue (Figs. 2-8, 14); lumen triradiate in posterior esophagus after hiatus. Nonsclerotized esophageal-intestinal valve extending into lumen of anterior intestine. Intestine without cecum. Nerve ring surrounding esophagus near its narrowest region, at posterior hiatus of esophageal lining. Deirids between nerve ring and excretory pore. Postdeirids sometimes indistinct. Excretory pore near but not beyond posterior end of esophagus. Tails typically pointed.

Male (based on 7 mature specimens): Body $3.8-5.7 \mathrm{~mm}(5.1 \mathrm{~mm})$ long by 243-402 (332) wide at esophageal intestinal junction, increasing to 286-406 (345) at greatest width, then decreasing to 197344 (270) at midventral sucker, approximately 14 times longer than wide. Esophagus 592-839 (754) in total length, 13.4-16.2\% (14.4\%) of body length; anterior dilation 170-205 (190) wide, posterior dilation 135-263 (211) wide; esophastome 329-344 (339) long. Esophageal-intestinal valve 39-43 (40) in length. Nerve ring 302406 (368) from anterior end. Dierids 519-692 (599) from cephalic end. Excretory pore near posterior end of esophagus, 530-637 (650) from anterior end. Gonoduct single, with testes reflexed $1.2-2.3 \mathrm{~mm}$ $(1.4 \mathrm{~mm})$ from cephalic end. Spicules subequal, with blunt noncapitate anterior ends, with posterior ends very slender and finely pointed; blunt ends of retracted spicules anterior to precloacal sucker and anterior pair of caudal papillae; right spicule 817-1,149 (973) long; left spicule 890-1,211 $(1,038)$ long, wider, more robust than right spicule, slightly longer than right spicule, $19-24 \%$ (21\%) of body length. Spicule ratio (right: left) 1:1.1-1.6 (1:1.2). Gubernaculum relatively small, 43-62 (56) long. Precloacal sucker ventral, 197251 (212) long, composed of 16-20 muscle units, 8 to 10 per side, with posterior edge $548-1,041(825)$ or $14-18 \%$ (16\%) of body length from posterior end. Anus (vent) marked by prominent transverse anterior lip, often open with tip of gubernaculum exposed. Caudal papillae 10 pairs, 6 large pairs preanal, 4 pairs postanal, plus pair of phasmids (Figs. 9, 10); first pair anterior to ventral sucker; second pair immediately posterior to sucker; third pair midway from sucker to anus; 3 closely adjacent pairs of papillae in longitudinal ventrolateral rows, with single papilla lateral to middle pair of these; anterior 2 pairs and lateral pair of these adjacent pairs preanal; postanal 3 pairs toward end of tail, with 2 pairs ventrolateral, with 1 pair usually dorsolateral. Phasmid paired, lateral, anterior to 3 posterior pairs of papillae; papillae system of Petter (1974) (Figs. 9, 10): pairs numbered 1,2, 3 preanal, ventral; pairs numbered 4, 5, 6, 7 adanal, with pair 4 lateral and occasionally variable in position, with pairs 5-7 ventral; pairs numbered $8,9,10$ postanal, with pair 8 lateral, with pairs 8 and 9 ventral, with pair 9 closer to pair 10 than to pair 7. Caudal end without alae, bending ventrally but not coiled. Tail 170-248 (221) long.

Female (6 specimens): Body 5.2-6.8 $\mathrm{mm}(5.9 \mathrm{~mm})$ long by $321-$ 450 (380) wide at esophageal-intestinal junction, increasing to 366453 (403) at greatest width, approximately 16 times longer than wide, with width then decreasing to 336-425 (375) at vulva, with body tapering only slightly to anus. Esophagus 692-969 (793) in total length, 

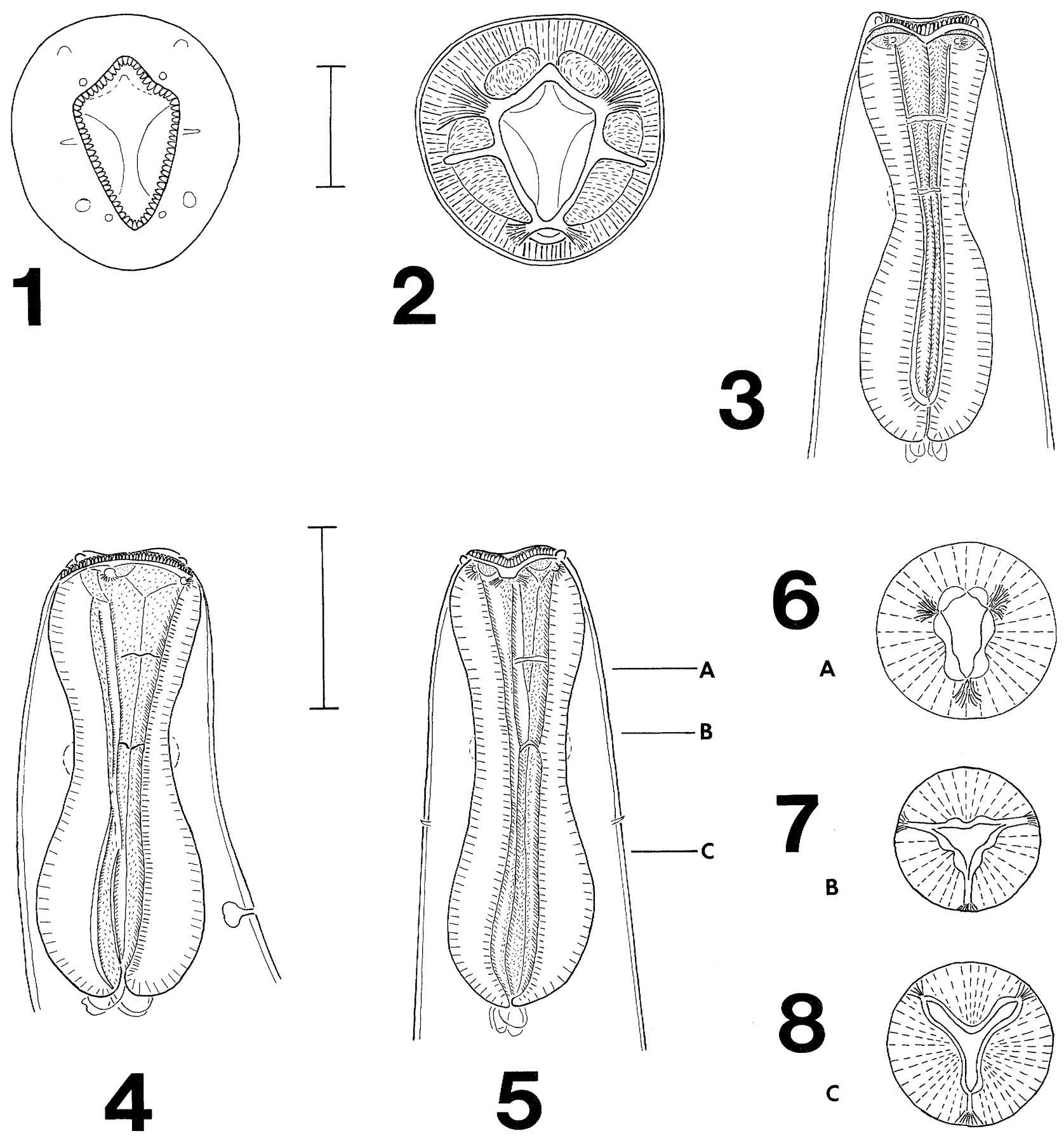

FIGURES 1-8. Cucullanus palmeri $\mathrm{n}$. sp. from Ogcocephalus nasutus. 1. En face view, showing relationship among mouth, denticular collarette, and external lateral amphids. 2. Optical section, showing buccal frame (esophastomal ring), ventral plate, lateral extensions, and muscle attachments. Scale bar $=100 \mu \mathrm{m}$; same scale for Figures 1 and 2 and Figures 6-8. 3. Anterior end, dorsal view. 4. Anterior end, lateral view. 5. Anterior end, ventral view. Letters A, B, and C indicate where cross-sections were observed. Scale bar $=300 \mu \mathrm{m}$; same scale for Figures 3-5. 6. Cross-section of esophagus at level near middle of esophastome, anterior to posterior hiatus, at level A. 7. Cross-section of esophagus near posterior end of esophastome near posterior hiatus, at level B. 8. Cross-section of posterior esophagus, at level C.

$11.8-14.4 \%(13.4 \%)$ of body length; anterior dilation 182-255 (211) wide, posterior dilation 194-290 (224) wide; esophastome 386-431 (416) long. Esophageal-intestinal valve 38-50 (44) in length. Nerve ring 305-420 (345) surrounding esophagus at posterior hiatus of esophageal lining. Deirids 519-625 (599) from cephalic end. Excretory pore near base of esophagus, 643-842 (706) from anterior end. Vulva usually salient, $2.7-3.9 \mathrm{~mm}(3.3 \mathrm{~mm})$ or $52-60 \%(56 \%)$ of body length from anterior end; ovejector muscular; vagina anteriorly directed, weakly muscular; uterus didelphic, amphidelphic, reflexed; each uterine sac associated with single ovary; gonoducts reflexed extending to $1.1-1.8 \mathrm{~mm}$ $(1.4 \mathrm{~mm})$ from anterior end of body, 400-993 (850) from posterior end. Eggs (those containing cleaving embryos in distal portion of uterus) 71-81 (77) long by 46-52 (49) wide. Intestinal-rectal valve muscular, forming constriction of digestive tract directly anterior to rectum; rec- 

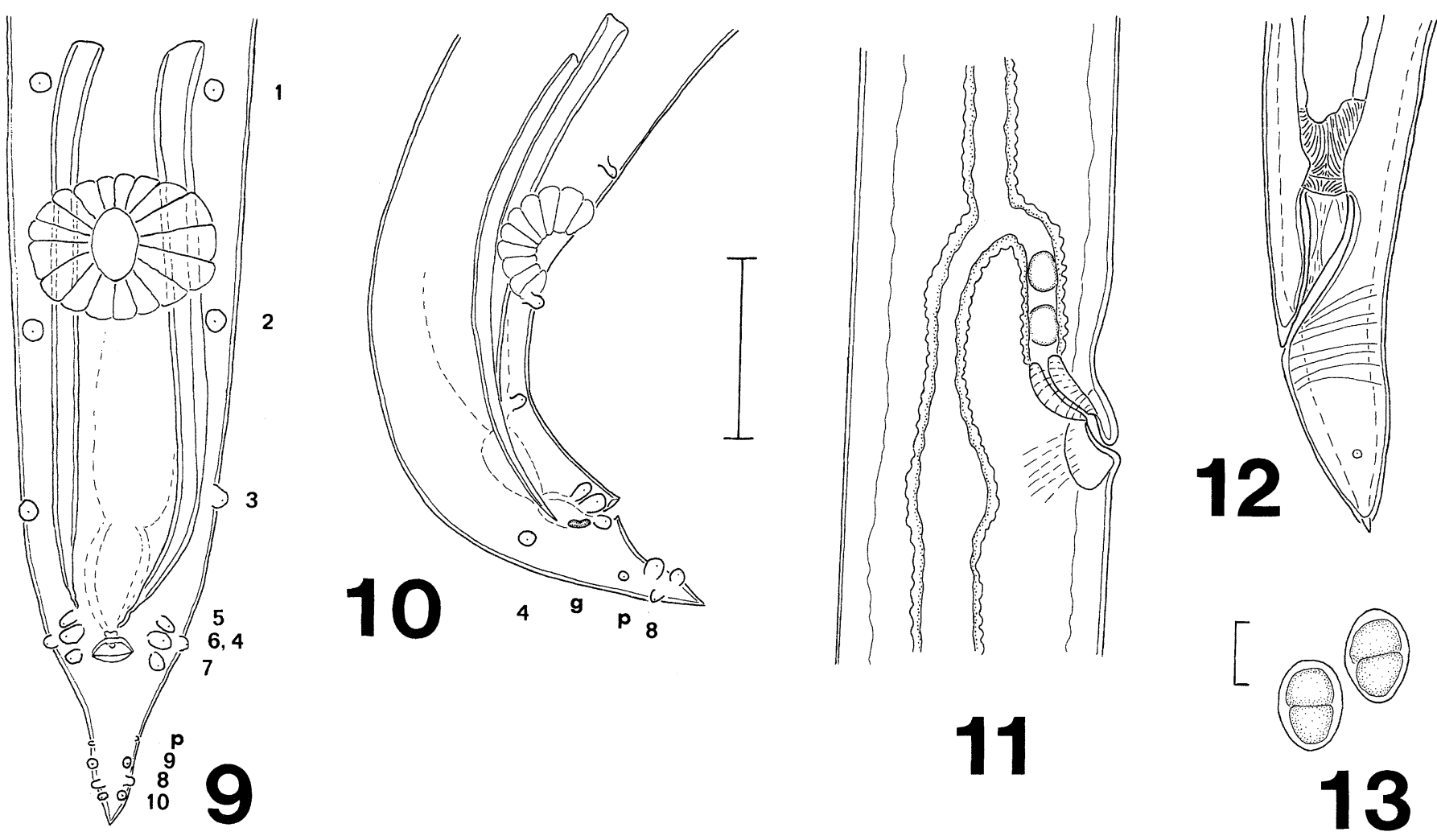

FIGURES 9-13. Cucullanus palmeri n. sp. from Ogcocephalus nasutus. 9. Male posterior end, ventral view showing disposition of caudal papillae in relationship to ventral sucker, spicules, gubernaculum (g), phasmid (p), and open anus. Papillae numbered using the system of Petter (1974). 10. Male posterior end, lateral view showing relationship of papillae, ventral sucker, spicules, gubernaculum, phasmids, and open anus. 11. Female lateral view demonstrating the relationship of ovejector complex, anteriorly directed vagina, and amphidelphic uteri. 12. Posterior end of female, lateral view, showing intestinal-rectal valve, rectum, anal muscles, and phasmid. Scale bar $=300 \mu \mathrm{m}$; same scale for Figures $9-12$ 13. Eggs freed from uterus. Scale bar $=50 \mu \mathrm{m}$.

tum with strongly sclerotized walls, 279-310 (295) long. Rectal glands difficult to discern. Anus transverse slit. Tail relatively long, 252-426 (335), conical, pointed. Phasmids 129-133 (132) from tip of tail. Tip of tail mucrone-like, 16-19 (18) long.

\section{Taxonomic summary}

Type host: Ogcocephalus nasutus (Valenciennes, 1837) (Pisces: Ogcocephalidae) shortnose batfish.

Site: Intestine.

Type locality: Gulf of Mexico. Hosts were caught by shrimp trawler, probably offshore from Louisiana or Texas.

Specimens deposited: Holotype (male), National Museum Parasite Collection, USNPC no. 86403; allotype (female), USNPC no. 86404; paratypes (4 males, 4 females), USNPC no. 86405; and H. W. Manter Laboratory, University of Nebraska State Museum, HWML no. 38984 ( 1 male and 1 female).

Etymology: This species honors Ronnie G. Palmer, whose superb technical assistance has contributed greatly toward advancing marine parasitology at the Gulf Coast Research Laboratory.

\section{Remarks}

On the basis of overlap of most measurements in both sexes and in the male the general arrangement of caudal papillae, position of caudal sucker, and approximate relationship between spicules, $C$. palmeri seems most anatomically similar to Cucullanus gendrei described by Campana-Rouget (1957) from the bothid flounder $S y$ acium micrurum Ranzani off West Africa. We obtained from the Museum National D'Histoire Naturelle (Paris) for comparison with this incompletely understood species 1 mature female specimen and 1 immature female specimen that were used for the description of
C. gendrei by Campana-Rouget. Cucullanus palmeri has a collarette with 60-80 (71) denticles; the collarette of $C$. gendrei has 55 (range unknown). The esophagus of $C$. palmeri in both sexes is shorter than that of $C$. gendrei, $12-16 \%$ of the body length compared with 19$22 \%$. The esophastome of $C$. gendrei is more shallow and the lumen narrows more anteriorly than in $C$. palmeri. Males of $C$. palmeri are generally larger in size with a longer tail than those of $C$. gendrei. Distal tips of the subequal and usually longer spicules are sharply pointed in C. palmeri (Figs. 9, 10, 17, 19, 20) but are illustrated (Campana-Rouget, 1957) as broadly rounded for those of near equal length in C. gendrei. The gubernaculum is smaller (43-62 vs. 145$1,160 \mu \mathrm{m})$ in C. palmeri. The fourth pair of papillae in C. palmeri, using the system of Petter (1974), is typically dorsolateral to the sixth pair rather than the seventh pair like in C. gendrei. Females of $C$. palmeri have a salient rather than nonsalient vulva like $C$. gendrei. Eggs average larger ( $71-81$ by $46-52$ rather than $60-75$ by $40-$ $45 \mu \mathrm{m})$. The rectum is longer and more thickly sclerotized in $C$. palmeri, and the tail is usually longer compared with that in $C$. gendrei.

Previously, the only cucullanid nematode known from fish of the order Lophiformes, which includes the batfish, was Cucullanus lophii Campana-Rouget and Chabaud, 1956, reported by CampanaRouget and Chabaud (1956) from the monkfish Lophius piscatorius Linnaeus in the French Mediterranean area. Cucullanus lophii can readily be distinguished from $C$. palmeri because the deirids and excretory pore of $C$. lophii are posterior to the posterior end of the esophagus. Males and females of $C$. lophii are larger than those of C. palmeri, but their esophagus remains in approximately the same proportion to the body length, whereas the tails of both sexes are shorter than those of $C$. palmeri. The spicules of $C$. lophii are longer, $28 \%$ of the body length compared with $20 \%$. The vulva of $C$. palmeri 

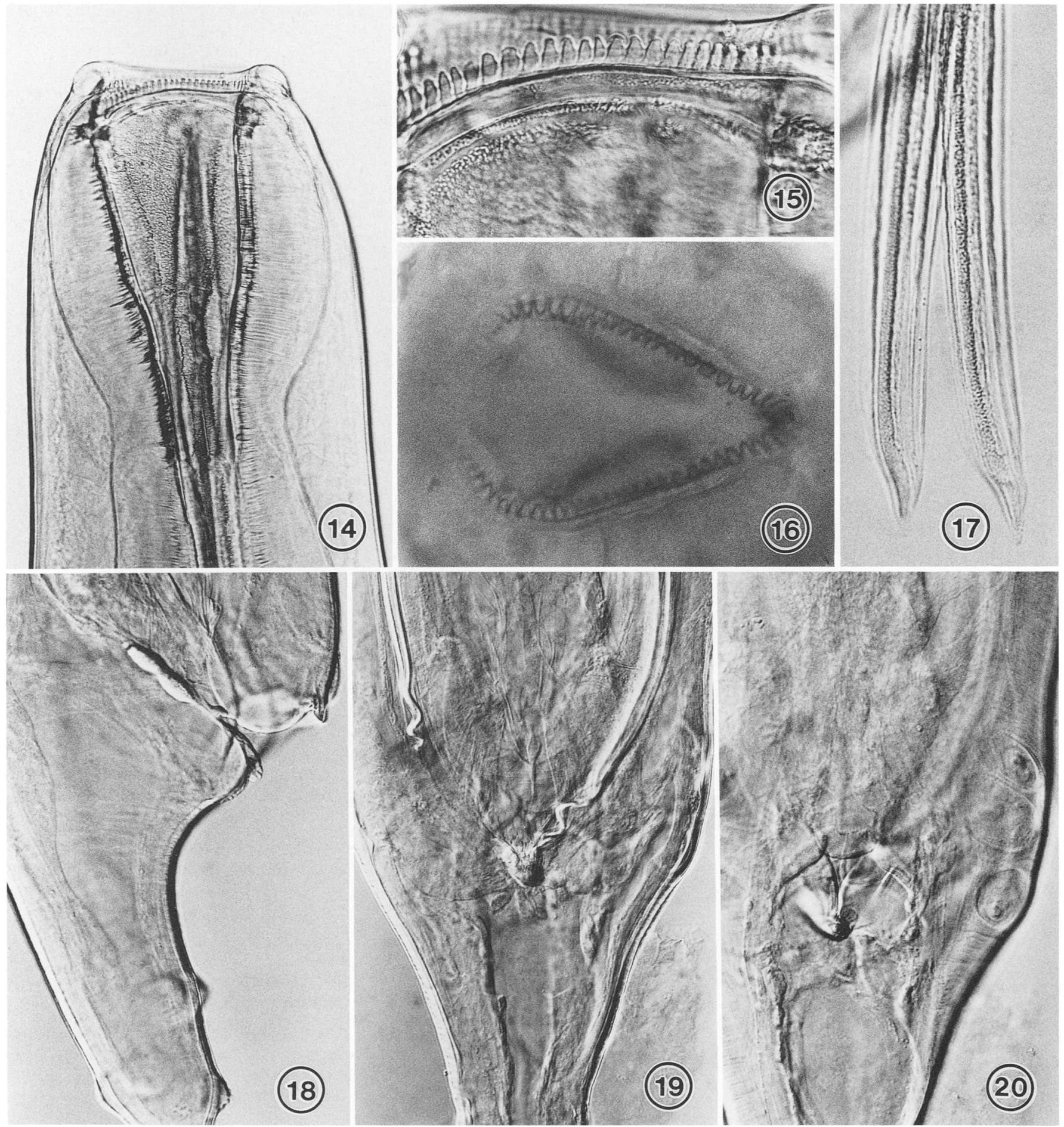

FiguRES 14-20. Optical sections of Cucullanus palmeri n. sp. from Ogcocephalus nasutus. 14. Esophastome, ventrolateral view, showing relationship among buccal ring, denticular collarette, and roughened walls with sutures and processes extending into esophageal muscles. 15. Anterior end, showing relationship of buccal ring to denticular collarette and roughened wall of the esophastome. 16. En face showing denticular collarette. 17. Pointed ends of extended spicules. 18. Caudal end, lateral view, showing open anus with thickened lips and posterior relative to gubernaculum and posterior papillae 8, 9, and 10 (see Figs. 9, 10). 19. Male, caudal end, ventral view, at level of anus showing relationship of spicular canals and gubernaculum. 20. Male, posterior end, ventral view showing left adanal papillae 5, 6, and 7, and open anus. 

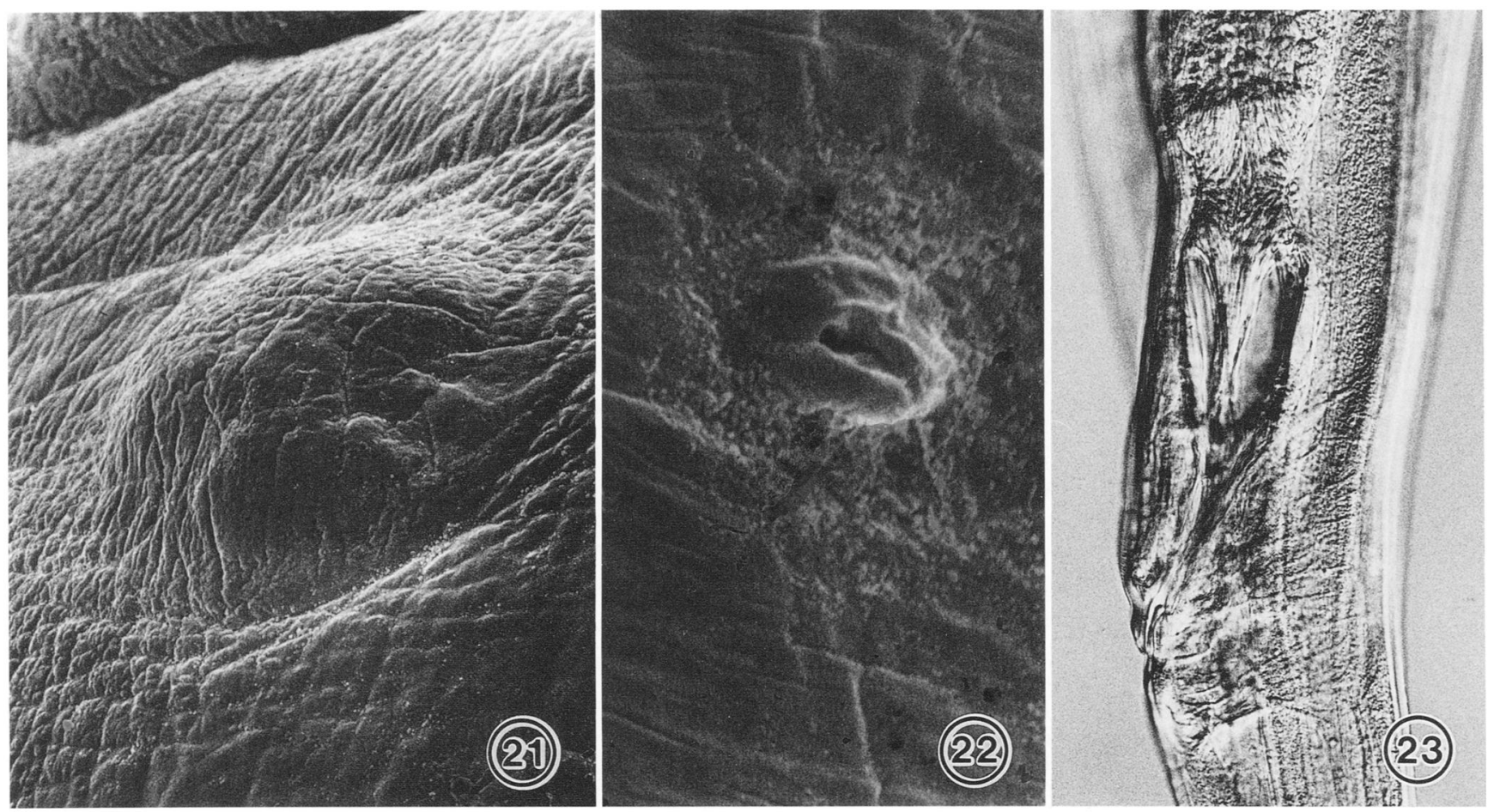

FIGURES 21-23. Cucullanus palmeri n. sp. from Ogcocephalus nasutus. 21. SEM, large ventrolateral papilla of the external circle. 22. Small papilla-like phasmid on female tail. 23. Female caudal end, lateral view, showing intestinal-rectal valve, sclerotized rectal walls, and anal muscles.

is proportionally closer to the anterior end than in females of $C$. lophii.

\section{DISCUSSION}

The anatomy of the head and esophagus of $C$. palmeri conforms in a general manner to that described by Berland (1970) for Cucullanus cirratus Müller, 1777, Cucullanus heterochrous Rudolphi, 1802, and Cucullanus minutus Rudolphi, 1819. There are 4 larger outer papillae and 4 smaller inner papillae, with 2 lateral amphids (Figs. 1, 14, 16). Using SEM, we revealed the cephalic papillae of $C$. palmeri to be single and not double as described by Baker (1984) for the cucullanid Dichelyne ( $\mathrm{Cu}$ cullanellus) cotylophora (Ward and Magrath, 1917). The esophastome (pseudobuccal capsule) consists of a sclerotized, anterior, dorsoventrally elongate, shield-shaped ring having strong, extraordinary muscle attachments. Laterally, there are short extensions from the ring over the anterior surface of the esophageal muscle, and, ventrally, the ring ends as a transverse plate provided with very strong muscle attachments. The ring supports the denticular collarette externally and extends posteriorly forming the lining of the esophageal lumen (Figs. 1-8, 14-16). The funnel-like lumen of the esophastome remains dorsoventrally elongate (Fig. 6) until just anterior to the posterior hiatus where it becomes triangular (Fig. 7). Posterior to the posterior hiatus, the lumen becomes triradiate (Fig. 8). The internal surface of the lumen lining is roughened, and each wall appears to be composed of plates separated by sutures. At the posterior end of the esophastome, in the narrow area of the esophagus surrounded by the nerve ring there is a prominent suture that Berland (1970) termed the hiatus. The esophastome of $C$. palmeri has this usual hiatus, but it also has a more an- terior hiatus that was consistently present in all specimens examined (Figs. 3-5, 14). At present, $C$. palmeri is the only species known to have a second hiatus anterior to the nerve cord.

We find it easier and more understandable in discussing the caudal papillae of the male to use the system proposed by Petter (1974) in her essay on the classification of Cucullanidae, in which she modified a system first used by Campana-Rouget and Chabaud (1956). Petter's system numbers the papillae pairs from anterior to posterior, 1-10, with papillae pairs 4 and 8 being lateral. Papilla 4 in C. palmeri is preanal (Figs. 9, 10), which is different from many other species of Cucullanus. Petter (1974) also proposed a scheme for demonstrating the evolution of anatomical characters in the family Cucullanidae, and she pointed out that papillae pairs 7 and 9 were always farther apart in species of Cucullanus than in species of other cucullanid genera. The seventh and ninth papillae of $C$. palmeri fit this pattern (Figs. 9, 10, 18). The gubernaculum of $C$. palmeri is smaller than in most species of Cucullanus, and its distal tip appears above the anus in ventral view (Figs. 9, 19, 20). The male anus is widely open in $C$. palmeri, and even though the walls of the cloaca do not appear heavily sclerotized, the lips of the anus are firmly sclerotized and protrude dorsally and ventrally (Figs. 10, 18). According to Tornquist (1931), the male "rectum" of species of Cucullanus is triangular in cross section and has a Y-shaped lumen. He proposed that this condition might be typical in all cucullanid nematodes. Berland (1983), using SEM, demonstrated a Y-shaped lumen between the "rectal lips" protruding through the anus of Cucullanus elongatus Smedley, 1933. Even though the anus of $C$. palmeri is widely open, we could not directly confirm a Y-shaped cloacal lumen for this species. The proximal, blunt ends of the 
retracted spicules of $C$. palmeri are always anterior to the ventral sucker and to the anterior pair of caudal papillae. This feature aids in distinguishing $C$. palmeri from other species of Cucullanus, in which this combination does not occur. The distal ends of the spicules are pointed and appear straight when extended (Fig. 17). When retracted, the spicules are pointed, but they may appear wavy and are contained in definite spicular canals (Fig. 19). The spicular canals reach posteriorly to the gubernaculum, but the gubernaculum is not $\mathrm{Y}$-shaped with sclerotized arms extending into the spicular canals as demonstrated for some other cucullanid species (Berland, 1970, 1983; Petter, 1974).

The vulva of $C$. palmeri is a transverse slit between two slightly salient lips. The vulva leads inside into a chamber with sclerotized cuticular walls and is surrounded by an ovoid mass of firm connective tissue set off from the surrounding hypodermis and provided with its own retractor muscles. The lumen of the antechamber with sclerotized walls enters and continues through a short, anteriorly directed, muscular tube. This muscular tube plus the antechamber make up the ovejector complex. The ovejector complex connects anteriorly with the vagina that continues anteriorly and then divides, forming both an anterior and posterior uterus (Fig. 11). The ovejector complex is seldom noted, but that in $C$. palmeri may be typical of all cucullanids.

The intestinal-rectal valve of both sexes has muscle cells giving it a decided sphincter-like appearance; this valve is best observed in females of $C$. palmeri (Fig. 12). The rectum of the female has a thickly sclerotized lining of the lumen, and it is surrounded by an outer layer of tissue. Muscle cells occur in the lateral body walls dorsal to the anus (Fig. 12); we presume that contraction of these muscle cells opens the anus.

Initial nematode specimens sent to us were obtained from a batfish tentatively identified at the Dallas Aquarium as Ogcocephalus radiatus (Mitchill). Of 3 intact specimens of batfish later sent from the Dallas Aquarium, 2 were caught from Tampa Bay, Florida, and we determined them to be uninfected $O$. $r a$ diatus. The third, trawled by a shrimper from the northern Gulf of Mexico, was $O$. nasutus and was infected with both $C$. palmeri and the ascaridoid nematode Hysterothylacium ogcocephali (Olsen, 1952), also sent with the initial specimens. Whether $O$. radiatus actually serves as a host of $C$. palmeri has to be confirmed.

Cucullanus palmeri is the only nematode of the genus $\mathrm{Cu}$ cullanus to be described from a marine fish host in the Gulf of Mexico. Other cucullanid nematodes reported from fish hosts from the Gulf of Mexico are Dichelyne (Dichelyne) fastigatus Chandler, 1935 from the red drum, Sciaenops ocellatus (Linnaeus), and Dichelyne diplocaecum Chandler, 1935 from the blue catfish, Ictalurus furcatus (Lesueur) by Chandler (1935) and Dichelyne (Cucullanellus) bullocki Stromberg and Crites, 1972 from the killifishes Fundulus grandis Baird and Girard and Fundulus similis (Baird and Girard) by Overstreet (1983). Dichelyne diplocaecum cannot be assigned to a subgenus as it has no described male (Chandler, 1935). The host, Ictalurus furcatus, is generally considered a fresh or brackish water fish.

\section{ACKNOWLEDGMENTS}

Ronnie Palmer, Helen Gill, Marie Wright, Pamela Monson, and Nate Jordan from the Gulf Coast Research Laboratory, all provided some technical assistance. David Schleser, Aquatic Biologist, and Thomas Alvarado, DVM, of the Dallas Aquarium obtained the initial nematodes from batfish and provided fixed fish to examine. Annie J. Petter, Laboratoire de Biologie Parasitaire, Protistologie, Helminthologie, Museum National D'Histoire Naturelle, Paris, France, furnished specimens of $C$. gendrei for comparative study. Partial funding is from International Paper.

\section{LITERATURE CITED}

BAKER, M. R. 1984. Redescription of Dichelyne (Cucullanellus) cotylophora (Ward and Magrath, 1917) (Nematoda: Cucullanidae) parasitic in freshwater fishes of eastern North America. Canadian Journal of Zoology 62: 2053-2061.

BERLAND, B. 1970. On the morphology of the head in four species of Cucullanidae (Nematoda). Sarsia 43: 16-64.

- 1983. Redescription of Cucullanus elongatus Smedley, 1933 (Nematoda: Seuratoidea) from the lingcod Ophiodon elongatus Girard, 1854 from the Pacific coast of Canada. Canadian Journal of Zoology 61: 385-395.

Campana-Rouget, Y. 1957. Parasites de poissons de mer ouest-africains récoltés par J. Cadenat. Nématodes (4 $4^{\mathrm{e}}$ note) Sur quelques espéces de Cucullanidae. Revision de la sous-familie. Bulletin de 1'Institut Francais d'Afrique Noire 19A: 417-465.

- , AND A. G. Chabaud. 1956. Helminths des environs de Banylus III. Sur trois espéces de Cucullanus (Camallanoidea, Nematoda) parasites de poissons. Vie et Milieu 7: 267-279.

Chabaud, A. G. 1978. Keys to genera of the superfamilies Cosmocercoidea, Seuratoidea, Heterakoidea and Subuluroidea, no. 6. In $\mathbf{C I H}$ keys to the nematode parasites of vertebrates, R. C. Anderson, A. G. Chabaud, and S. Wilmott (eds.). Commonwealth Agriculture Bureaux, Farnham Royal, U.K., p. 1-71.

Chandler, A. C. 1935. Parasites of fishes of Galveston Bay. Proceedings of the U.S. National Museum 83: 123-157.

OverstreEt, R. M. 1983. Aspects of the biology of the red drum, Sciaenops ocellatus, in Mississippi. Gulf Research Reports, Supplement 1: 45-68.

PetTer, A. J. 1974. Essai de classification de la familie des Cucullanidae. Bulletin du Muséum National d'Histoire Naturelle Paris. Series 3, No. 255 (Zoologie 177): 1469-1490.

SCHLESER, D. M., AND T. P. Alvarado. 1992. Suggested aquarium husbandry for Ogocephalidae-The walking batfish. AAZPA [American Association of Zoological Parks and Aquariums] Regional Conference Proceedings. p. 1-4.

ToRnquist, N. 1931. Die Nematodenfamilien Cucullanidae und Camallanidae nebst weiteren Beitrögen zur Kenntnis der Anatomie und Histologie der Nematoden. Götborgs Kungl. Vetenskaps och Vitterhets, Samhälles Handligar, Femte Följden 2B, 441 p. 